\title{
To the Mirror Image
}

$\{$ PAUL BEKKER

\section{Dear Mirror Image,}

You are astonished that I address you ceremonially, and that I avoid familiarity in my salutation. ${ }^{1}$ It is done seriously and deliberately. You live with the delusion that you are me. And you are not the only one to take yourself for me: the whole world shares this mistake, and knows nothing of any difference between you and me, and nothing at all about my existing outside your world. I know, however, that you only seem to be me. I see the deception with which you imitate my lineaments, my movements, my speech, to present me to the world, this mirror world, that never is able nor wants to recognize man himself, but only his soulless reflection.

Therefore, I intend to separate myself from you here and now; I want to speak with you and settle accounts with you. You shall answer to me, me myself; I who know myself to be not an other, as you are wont to portray me. Hence, there is no connection between us now, no sparing or holding back. Therefore I dissociate myself from you and beseech you to avoid all treacherous comradeship and only aspire to be nothing else than what you are in reality: a mirror image, product of unfamiliar brains, which I confront with my own self.

But how do I enter this society, the society of contemporary musicians? Do I belong here? Mind you, there are a number of very illustrious names among them, whom I would certainly never consider to place myself alongside. I believe, however, that as a faithful minstrel I might nevertheless deserve a little place in the corner, and that one should not take issue so strongly with a couple of wrong notes; for who could say he has always played correctly and well? Thus I join the ranks at the tail-end, trusting that any differences, seen from the proper distance, are not that enormous, and that it is not at all our intention here to find inequalities of measures and practices, but to recognize the particular idiosyncrasies of our inner motives.

And what is a poor writer to do? Of course, his books remain and could bear witness to him, if they were read, understood, and quoted properly. In reality, though, they are rarely read, not at all understood, and only incorrectly quoted. Even worse off is the critic, for each critical word about anybody will be paid back double. But how then does a theater director and producer fare? He falls in among thieves, his oeuvre blows away, and that is the end of him, even if he was the best.

The Opera Quarterly Vol. 23, No. 2-3, pp. 311-317; doi: 10.1093/oq/kbno43 Advance Access publication on October 16, 2008 (C) The Author 2008. Published by Oxford University Press. All rights reserved. 
Mirror image, you do not suit me! You suggest that I find you not handsome enough for me? On the contrary, you are sometimes too handsome. For indeed: uncomprehending critics may annoy us, but insincere flatterers are repugnant.

So that's not what it is I dislike about you, mirror image. You lack something that belongs to me, an attribute, the only one that I value and that always accompanies me-Diogenes' Lantern. That's what's missing in you, and so I say: mirror image, something is not right with you.

The tasks of men are diverse, and similarly diverse are the resources provided to them by nature: to one, it gives the gift of inquiry, to another, the genius of creation, and so on in the most manifold varieties. To me, it gave the longing for mankind, the urge to look for it everywhere; and from it, from the idea of its existence, to recognize, to judge, and always to make others aware of this basic measure of value as such. I would not have known what else to cling to, if not to this one primal notion of the essence of all values, which appeared to me by and by in the most diverse phenomena, and seemed to me more and more glorious, and in its applicability more and more inexhaustible, until it became wholly the guiding principle of my thinking and acting.

But which kind of man, you ask. The one on the right, on the left, or in the middle? Mirror image, you are simple minded, but I know what you are aiming at, and I will help you in just a moment. Before that, I reply: the humane man, ${ }^{2}$ no other. It is him alone I have been after. I went the wrong way here and there, but the main direction was right. The distinctions you are drawing, though, mean nothing to me. From your objections, I can only conclude that you have not yet understood what I really mean. One does not go in a direction for the sake of the direction, but because this direction is the shortest way to one's destination. The direction cannot be the end in itself. If one disregards the destination, then one goes on seeking the way that guides us according to the original movement: that is, to man. He is not only the measure; he is also the goal of all things. Therefore, I repudiate you, mirror image, because you do not recognize the very thing that is the most important for me, and the explanation for everything. Therefore, I call you a caricature.

Figures of speech! you exclaim. But you wouldn't even know where to start with this notion of the "human."

I do not want to disconcert you straightaway and ask which other fundamental ideas, which notions of value, which guideposts and keys to inner sources of power you can name. Let us first see what we can achieve my way.

Can you explain to me how a musical value judgement, be it of a sonata or a symphony, is actually accomplished, and by which laws you approve of this ensemble, or battle against that one? You will admit to me that the judgement of technical ability or inability has to be made early on merely as an academic issue, although even here some strange discrepancies arise. You will also admit that the 
so-called eternal laws of beauty are simply figures of speech, created for men who are not able or not willing to think. Aesthetics can only give us relative value at best. We ourselves have to supply a basic absolute, or everything we deduce will remain hanging in the air.

Now I ask you for your own basic measure for favor and disfavor beyond all academic ideas of technique and aesthetics. Do you have a formula, a nostrum, or a divining rod that twitches at the right moment? Or how do you do it? At some point you must learn how you are to think and what you are to judge. Mirror image, do not dodge the question! Confess, and answer me! What, you cannot? Sure enough, how should you; you are just a mirror image, and a false one at that.

So listen: I place human authenticity and veracity in itself, and the profundity and greatness of mankind as the ultimate touchstone.

You smile and maintain that if this were the case, confusion would just increase. Certainly, I know that there are many religions. But I do not in any way claim that my conception of human authenticity and veracity is able to apprehend and exhaust everything. I only say that the reference to and the inner alignment with these qualities gives us the only reliable possibility of gaining a criterion for the matters of art, while, at the same time affording us a continual sharpening of our ability to value. For every criticism is double-sided. It says just as much about the critiquing subject as about the criticized object. It does not happen by taking a standard-issue tape measure out of our pocket and applying it to the victim; it happens when we reveal ourselves and engage in discussion with him. What kind of common ground, however, would enable us to do that, if we did not have-beyond the auxiliary terms of technique and aesthetics-the basic notions of authenticity and veracity derived from mankind itself?

I admit that today the common method is completely different. But are not the results the same? We operate with progress and setbacks, with the up-to-date and the obsolete, and, depending on our camp, admire what belongs to our group or chastise what belongs to the others. It is hard to say whether this spectacle is more ludicrous or distasteful. Above all, it is indescribably ignorant, and this ignorance naturally transmits itself into the judgment of the reproducing activity.

But the damage done there is considerably greater. The creator can be pleased and inspired by sympathetic encouragement, or embittered or annoyed by lack of comprehension - in the end, though, he continues on his way, as his own law directs him. For the re-creator, it is much more difficult. He is not only weaker than the creator by nature, but is moreover more directed towards the sympathy and the encouragement of his contemporaries. Not only does he live from them economically, but he also needs them for active resonance.

Here, too, I believe indeed in the mysterious force of the power of real humanity that asserts itself even if it is not recognized in its actual nature. 
Nevertheless, there are domains where the awareness of a basic norm is indispensable, and the absence of this awareness is a threat to existence. I think of the theater: theater in general as a phenomenon of our public life, theater as the genre of opera and plays, and finally, theater as a performance task for singers, actors, and their aides.

I ask you: what do you make of the multiplicity of these phenomena? You think some are good, others bad; it is the opposite for me: I ask you for your "why," but you just enjoy the variety of these busy energies, which, as you say, correspond to the multiplicity of life. It is a pity, though, that there remains an unbreachable abyss between this multiplicity of art and the multiplicity of life. Life may speak to us from different phenomena-the creative original power stays the same. It is the same mystery in the greatest genius as in a beetle or in a blade of grass. In the realm of natural creation, any value judgment may and should cease because we are equipped with far too humble organs of awareness to be allowed to apply measures.

For the arts, that does not hold. Here we are the masters, the creators ourselves. So here we may and should judge, namely with the measure that is the highest one for us with regard to the created: with us ourselves, with the man, who here is God.

Thus the manifestation of art is through and through a reflection of the measure and the particular power of man. Which kind of human power, though, could it be, if not the power of the most intense closeness to nature, that is, the elemental veracity of most genuine humanity!

Once again, and seriously asked: what other basic notions of value judgment can you specify to me? We do not have to talk about progress and setbacks, about the up-to-date and the obsolete anymore. We only want to denote the psychologically remarkable fact that, beginning with a certain stage of maturity, the representatives of both groups are in the habit of exchanging their names; so, the erstwhile progressives become reactionaries, and reactionaries-with particular pride-become progressives. That also holds true for the groups as a whole. Do you know something else, mirror image? I am afraid we end up with the fact that this man is your good friend, and that woman has always been fundamentally unappealing to you. When you are finally at a loss, you will cite Goethe who said that "emotion is everything," and in ultimate despair, you will finally proclaim the freedom and subjectivity of criticism.

Let us avoid this labyrinth and rather calmly and tightly seize the measure that nature has placed in our hands and before our eyes for any decision: man himself. I dare say this holds true for decisions other than of an artistic kind, but those shall not interest us here. I only mention them because I am convinced of the necessity of an inner unification of art and life. This unification is a pre-condition for overcoming that chaos in which we currently stagger around. 
Have a look at the addressees of my letters: who of them has attained this unification? Only one: Richard Strauss - and he stands there as the victor, acknowledged by all others, whatever arguments they otherwise put forward against him. Why? He managed to bring art and life together in a formula by giving them the common denominator of man. Let us leave unspoken the question whether it is really the man of Straussian coinage who might be considered by us as goal and type. This comparison with other types is going to come and is another story. However, there is an overall type, and he can be proud of himself. You can cut through him to the root of his being; he will prove to be authentic and true in himself.

That is a lot, mirror image; do respect it, for no one among the others has imitated him. Only one would I name in this context, but he is not among the living anymore: Busoni, who elucidated and got to the core of things from a completely different angle, while Mahler was broken by the contradictions of the extremes. But have all the rest even attempted and wanted something similar? I am afraid not. They wanted Art, or the party, or weltanschauung, or some other beautiful thing-but they did not want man.

How do we attain to man?

A delicate question, when it is put that way. Until the present day, it has not successfully been achieved to create him from a retort. But we still have ways to him that appear as soon as we begin to look for him and want to see him. This wanting would then be the first step. Nature has also given to mankind in music not only vague terms, but an absolutely real or natural pattern for man: the voice.

I have already, in the preceding letter to the singer, pronounced that the singing human voice has the same importance for music as the human body for the visual arts. When our composers have truly grasped this once and for all, when they do not write for the voice as for any instrument, and also not, as they say, "singable," but entirely from their consciousness and the awareness of the peerlessness and uniqueness of this organ-then we will have true operas again.

But now, mirror image, I have to tell you why I am not satisfied with you, and do not regard you as my equal. That is because you do not know that I, again and again, recognized the character and form [Gestalt] of the human voice as canonical for music and any form of composite art for which music is the strongest source, namely the musical theater. Tell me whatever you want; about reforms, about pervasion of the operatic gesture by dramatic movement, about reconfigurations of stage designs, about adapting old operas to the requirements of the contemporary audience-tell me about that and about a hundred thousand similar reform stories; let it be printed by every newspaper in the world by official decree, and every day at that; let it furthermore, by an unending speaking chorus ... but wherefore all this? I say to you very calmly and simply to the contrary: God is of the east possess'd, and opera of the singing human voice. As long as you do not derive and establish everything that you have in mind from the 
human voice alone; as long as you do not understand that opera is the manifestation of voices, and that these singing voices, as sound-incarnated human forms, are as much a measure for the opera as is man himself for the theater-as long as that is so, every single one of your reforms is just blind noise and not worth more than a dead cat. To that you may shout "victory" and "Hosanna" as much and as loud as you want. Here, belief does not stand against belief. Here, there is only one possibility of truth, and it is called man.

You see, mirror image-you could be much uglier than you are, and that would not bother me, if you would only let yourself acknowledge this one truth that I hold. For it is this truth I have advanced, and from it I have extracted the law. I have found that this law carries within it a wonderful inexhaustibility, and it seizes and enlivens everyone who encounters it; whereas the degrees of life intensity are naturally differentiated, according to the quality of the respective humanity. I have found further that this is the key with which it becomes possible to provide the various, seemingly conflicting, regions of social and economical questions with an organic denouement into the artistic: namely as soon as one succeeds in comprehending and understanding these questions from their common core "man."

I believe that this was, after all, a productive achievement. Now then, one could perhaps have said that it was well intentioned, just not well done. But if that were the case, one would have had to see it in the first place. Meanwhile, one could not judge it because one did not notice it at all, and one did not notice it because the organ that might notice it is not there at the moment. The contemporary mishmash of uncontrollable verdicts of taste judges according to "success." Success of this kind, however, may be based only on something that is generally noticeable from the beginning, something that pays with passable currency, and reenacts the usual phrases with most effective emphasis. That, however, was not my way, and not my goal. But I trust that this way and this goal will make themselves discernible and assert themselves with the respective necessity, just as the notion of man as the basic measure of art shall be newly discovered. For he is the only one from whom new power and new creativity can be obtained.

Mirror image, you know now what I do not like about you. I wish you were truthful, not for my sake, but because it is necessary for the spirit of truthfulness to inhabit men again, at least those who stand as exemplars for the others.

I have told you what was on my mind. So let's get along again, and adjust ourselves to each other as best we can. For we still cannot help but be bound and ensnared to each other indissolubly. So let's be friends again, and let's return to the more familiar greeting, ${ }^{3}$ for although I know that you are not me, even though you pass yourself as me-who cares? Sometimes, it can bother or annoy, especially when it occasionally gets too silly and a grimace appears in the mirror, which really is nothing more than a caricature. But this passes, and it is not that 
important in the end. What is important and remains alone in the end is what we are, not what we appear to be.

Come then, wicked old image. Each of us will do his part: you may seem; I will be. Perhaps we will once again find ourselves together. Then we shall try to find out once and for all which of us is the right one.

Translated by Martin Morgenstern and Nanette Nielsen with James Steichen

\section{NOTES}

This piece was originally published in German in Letters to Contemporary Musicians (Berlin: Max Hesses Verlag, 1932).

1. Bekker uses the formal Sie (you) instead of $d u$ throughout most of the text. Eventually, he changes to the informal salutation, where indicated. Accordingly, the salutation of the letter uses the formal "Sehr geehrter" instead of the familiar "Lieber" (both of which translate into English as "Dear").

2. Der menschliche Mensch (the humane man).

3. Here, Bekker switches from Sie to $d u$. 